\title{
The Importance of Complementary Information Provided by Surface Analysis, Electron Microscopy and in situ Characterization of Nanoparticles
}

\author{
D. R. Baer,* J. E. Amonette, ${ }^{* *}$ A. Dohnalkova, ${ }^{*}$ M. H. Engelhard, ${ }^{*}$ S. Kuchibhatla, ${ }^{*}$ J. Liu, ${ }^{* *}$ P. \\ Nachimuthu, ${ }^{*}$ J. T. Nurmi, ${ }^{* * *}$ P. G. Tratnyek, ${ }^{* * *}$ and C-M. Wang* \\ *Environmental Molecular Sciences Laboratory, Pacific Northwest National Laboratory, Richland \\ WA 99352 \\ **Fundamental and Computational Sciences Directorate, Pacific Northwest National Laboratory, \\ Richland, WA 99352 \\ ***Department of Environmental and Biomolecular Systems, Oregon Health \& Science University, \\ Beaveron OR 97006-8921
}

There is a growing recognition that many reports on the properties of nanoparticles and other nanostructured materials are sometimes based on inadequate characterization and that these limitations may invalidate some of the conclusions[1-2]. The need for several types of information about nanoparticles, including shape, size, and surface chemistry, has been identified by a variety of international organizations including the ISO Committee 229 on Nanotechnology [3-5]. High spatial resolution methods such as electron microscopy are routinely applied for characterization of nanoparticles. Less common, but equally important, it is necessary to understand the nature of the surfaces of nanoparticles $[1,6]$ including surface functionality, the presence of contamination, and the nature of surface coatings [3, 7-8].

Although XPS is not always considered a nano-analysis method it can be used to extract a great deal of information about nanostructured materials. The nano-structure of a material influences the relative peak ratio of photoelectron peaks, their binding energy and the energy loss or background signals [7]. This information can be used to extract information about layers on particles, particle size the presence of contamination or impurities and the nature of the oxidation state of elements near the particle surface. Although this information is available, it may require analysis that goes beyond the simple methods routinely applied for XPS analysis.

For several years our research has focused on the relationship between the physical and chemical structure of nanoparticles and their reactive behavior in a variety of environments. For the analysis of iron metal-core oxide-shell and ceria nanoparticles, we have found that a wide variety of tools are essential for adequate particle characterization including surface analysis[3, 7] (mostly commonly $\mathrm{x}$-ray photoelectron spectroscopy (XPS)), electron microscopy[9-10], and x-ray diffraction combined with complimentary methods (including optical and electrochemical) that can characterize particles in their working environment[11-12].

One of our research interests has been learning how particles change with time in a variety of environments[12]. This has included examining the impact of natural organic material (NOM) on the structure and reactivity of iron metal-core oxide-shell nanoparticles. We have used XPS to examine the nature of the NOM coating on the particles, TEM to examine the nature of the particles after solution exposure and the impact of the NOM. In addition to our normal sample extraction and drying process, we have used cryoTEM to examine the nanoparticles as they interact with the NOM in solution. 


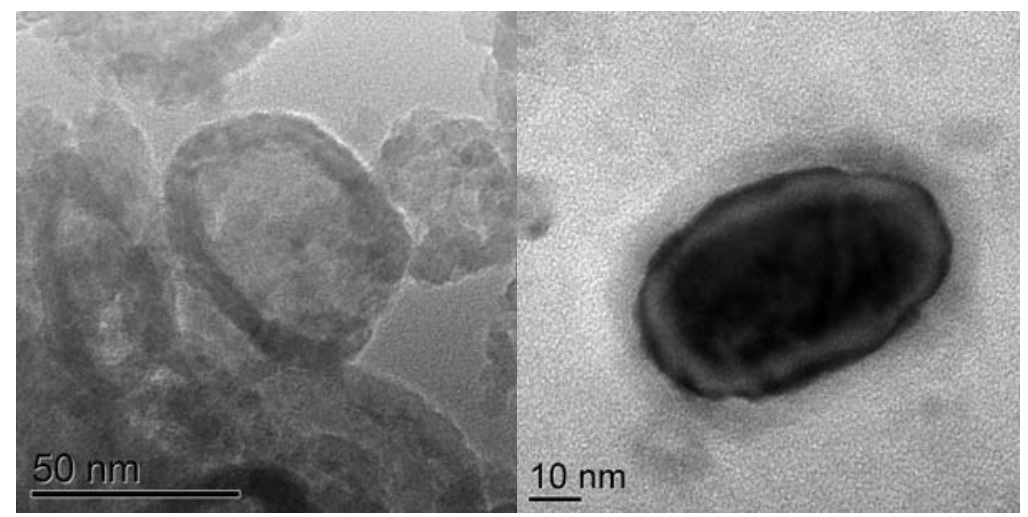

When iron metal-core oxide shell nanoparticle are exposed to solution containing natural organic material (NOM) for 24 hours both hollow oxide shells and intact particles with metal cores and oxide shells have been identified during cryoTEM measurements.

Acknowledgements: This work was supported by the U.S. Department of Energy (DOE) Office of Energy Research, Offices of Basic Energy Sciences and Biological and Environmental Research. Parts of the work were conducted in the William R. Wiley Environmental Molecular Sciences Laboratory (EMSL) a DOE User Facility operated by Battelle for the DOE Office of Biological and Environmental Research and located at Pacific Northwest National Laboratory.

1. Grainger, D.W. and D.G. Castner, Advanced Materials, 2008. 20(5): p. 867-877.

2. $\quad$ Stuart, C., Small Times, 2006. 6(2).

3. Baer, D.R., D.J. Gaspar, P. Nachimuthu, S.D. Techane, and D.G. Castner, Analytical and Bioanalytical Chemistry, 2010. 396 (3): p. 983-1002.

4. Boverhof, D.R. and R.M. David, Analytical and Bioanalytical Chemistry, 2010. 396(3): p. 953-961.

5. Ichimura, S., Analytical and Bioanalytical Chemistry, 2010. 396: p. 963-971.

6. $\quad$ Karakoti, A.S., L.L. Hench, and S. Seal, Jom, 2006. 58(7): p. 77-82.

7. Baer, D.R. and M.H. Engelhard, Journal of Electron Spectroscopy and Related Phenomena, 2009. In press.

8. Zhang, B. and B. Yan, Analytical and Bioanalytical Chemistry, 2010. 396(3): p. 973-982.

9. Wang, C.M., D.R. Baer, J.E. Amonette, M.H. Engelhard, J. Antony, and Y. Qiang, Journal of the American Chemical Society, 2009. 131: p. 8824-8832.

10. Wang, C.M., D.R. Baer, J.E. Amonette, Y. Qiang, and J. Antony, Nanotechnology, 2007. 18: p. 255603.

11. Nurmi, J.T., P.G. Tratnyek, V. Sarathy, D.R. Baer, J.E. Amonette, K. Pecher, C.M. Wang, J.C. Linehan, D.W. Matson, R.L. Penn, and M.D. Driessen, Environmental Science \& Technology, 2005. 39(5): p. 1221-1230.

12. Sarathy, V., P.G. Tratnyek, J.T. Nurmi, D.R. Baer, J.E. Amonette, C.L. Chun, R.L. Penn, and E.J. Reardon, Journal of Physical Chemistry C, 2008. 112(7): p. 2286-2293. 